\title{
Cardiology and Therapy: A Summary of 2018 and Key Areas of Emerging Research in 2019
}

Ian B. A. Menown · Robert P. Giugliano · Uwe Zeymer

Received: January 8, 2019 / Published online: January 25, 2019

(C) The Author(s) 2019

Keywords: Atrial fibrillation; Cardiology; GLP-1 analogs; Heart failure; Hyperlipidemia; Hypertension; PCSK9 inhibitors; Percutaneous coronary intervention; SGLT2 inhibitors; TAVI

\section{Dear Readers,}

As we look forward to 2019, and the year that lies ahead for Cardiology and Therapy, we feel it is important to reflect on the journal's highlights and successes from the previous year. We also acknowledge that all of this would not have been possible without our authors, readers, reviewers, editorial board members, advisory board members, and everyone else who has contributed to the journal over the past year. We would like to extend our immense gratitude and appreciation to you.

Throughout 2018, the journal saw an increase in readership from 2017, with over

Ian B. A. Menown, Robert P. Giugliano, and Uwe Zeymer contributed equally to this manuscript.

I. B. A. Menown

Craigavon Cardiac Centre, Craigavon, Northern Ireland, UK

R. P. Giugliano $(\bowtie)$

Brigham and Women's Hospital, Boston, MA, USA

e-mail: rgiugliano@bwh.harvard.edu

U. Zeymer

Klinikum der Stadt Ludwigshafen, Ludwigshafen am Rhein, Germany
190,000 downloads from SpringerLink and PubMed! A selection of the most highly read articles for the journal in 2018 include:

- Singh A, Saluja S, Kumar A, et al. Cardiovascular Complications of Marijuana and Related Substances: A Review. Cardiol Ther. 2018; 7:45. Available at: https://link. springer.com/article/10.1007/s40119-017-01 02-x (5500 downloads, 33 shares, and 3 citations since publication)

- McKavanagh P, Yanagawa B, Zawadowski G, et al. Management and Prevention of Saphenous Vein Graft Failure: A Review. Cardiol Ther. 2017; 6:203. Available at: https://link. springer.com/article/10.1007/s40119-017-00 94-6 (2500 downloads, 2 shares, and 1 citation since publication)

- Mahtta D, Elgendy IY and Bavry AA. From CoreValve to Evolut PRO: Reviewing the Journey of Self-Expanding Transcatheter Aortic Valves. Cardiol Ther. 2017; 6:183. Available at: https://link.springer.com/ article/10.1007/s40119-017-0100-z (2200 downloads, 1 share, and 3 citations since publication)

- Bromley A. and Plitt A. A Review of the Role of Non-Vitamin K Oral Anticoagulants in the Acute and Long-Term Treatment of Venous Thromboembolism. Cardiol Ther. 2018; 7:1. Available at: https://link.springer.com/ article/10.1007/s40119-018-0107-0 (1800 downloads and 12 shares since publication) 
- Saraiva JFK. Stroke Prevention with Oral Anticoagulants: Summary of the Evidence and Efficacy Measures as an Aid to Treatment Choices. Cardiol Ther. 2018; 7:15. Available at: https://link.springer.com/article/10.1007/ s40119-018-0106-1 (1600 downloads and 7 shares since publication)

In 2018, all published articles were accompanied by a summary slide, and we have also been encouraging the use of other enhanced content to accompany published articles. We were delighted to publish a video alongside the following case report titled, "Pulmonary Embolism Following Incomplete Surgical Resection of a Right Ventricular Myxoma: A Case Report and Review of the Literature." The video can be viewed here: https://doi.org/10.6084/m9. figshare.6061451.

During the previous year, we have continued promoting Plain Language Summaries to authors, and have published articles with these. Plain Language Summaries are published as part of the article, beneath the abstract, and their purpose is to assist non-experts (including nonspecialists, patients, caregivers and others) in understanding important medical advances. An example published in Cardiology and Therapy in 2018 can be seen here: https://link.springer. com/article/10.1007/s40119-018-0110-5.

Our increasing presence on social media has been a particular highlight also, and the journal's Twitter account (@Cardio_Therapy) now boasts over 370 followers. Tweets are sent out when articles are published online in the journal, and during conferences and relevant cardiology days.

As we look to the year ahead, the main topics of interest are listed by all three of our Editor in Chiefs below.

Ian Menown predicts there to be interest in antiplatelet duration post-percutaneous coronary intervention with regards to when and how to go short, and when to prolong. Other topics of relevance include the role of low-dose rivaroxaban $2.5 \mathrm{mg}$ bd plus aspirin for stable coronary artery disease, new guidelines and therapy options in hypertension, guideline updates in hyperlipidemia including re-evaluation of elevated triglyceride therapy options, latest data regarding inflammation and atherosclerosis, heart failure guidelines and therapy options, and the optimum antiplatelet and anticoagulant approach for patients with atrial fibrillation, elevated CHADSVASC score and recent percutaneous coronary intervention.

Robert P. Giugliano states that in 2019, we look forward to further advances in the fields of lipids, diabetes, and heart failure. New information with PCSK9 inhibitors and other lipidmodifying therapies, SGLT2 inhibitors and GLP1 analogs, and novel treatments for heart failure are highly anticipated in the New Year. In addition, as cardiovascular medicine expands it horizons, areas such as cardio-oncology and cardio-metabolic medicine are likely to produce a wealth of exciting new data.

Uwe Zeymer thinks that the treatment of patients with left ventricular thrombus, optimal antithrombotic therapy after transcatheter aortic valve implantation, and the current status of mechanical support in cardiogenic shock will be topics of interest for the next calendar year.

In summary, Cardiology and Therapy is looking forward to the year ahead and wishes you all a Happy New Year!

Ian Menown, MB BCH BAO, MD, MRCP (UK), FRCP (Edin)

Robert P. Giugliano, MD, SM, FACC, FAHA

Uwe Zeymer, MD

\section{ACKNOWLEDGEMENTS}

This commentary is authored by the three Editor-in-Chiefs of the journal and has not been peer reviewed.

Funding. No funding or sponsorship was received for this study or publication of this article.

Authorship. All named authors meet the International Committee of Medical Journal Editors (ICMJE) criteria for authorship for this article, take responsibility for the integrity of the work as a whole, and have given their approval for this version to be published. 
Disclosures. Robert P. Giugliano, Uwe Zeymer, and Ian B. A. Menown have nothing to disclose.

Compliance with Ethics Guidelines. This article does not contain any studies with human participants or animals performed by any of the authors.

Open Access. This article is distributed under the terms of the Creative Commons
Attribution-NonCommercial 4.0 International License (http://creativecommons.org/licenses/ by-nc/4.0/), which permits any noncommercial use, distribution, and reproduction in any medium, provided you give appropriate credit to the original author(s) and the source, provide a link to the Creative Commons license, and indicate if changes were made. 